\section{A Colour Atlas of Gynaecological Surgery}

Vol. 2. Abdominal Operations for Benign Conditions. By

David H. Lees and Albert Singer. Pp. 288, illustrated.

Wolfe Medical Publications: London, 1978. $£ 26.00$.

The authors' aim has been to produce a series of Atlases that provide detailed instructions in the techniques of standard gynaecological operations by using step-by-step life-size photographs in natural colour, with an accompanying commentary. They make it clear in the introduction to both volumes that it is not their intention to cover the indications for either operative treatment, or pre-operative or postoperative treatment. Volume 1 covers: Dilatation and curettage; diathermy coagulation of the cervix; cryosurgical treatment of cervical erosions; removal of submucous fibroid polyp by vaginal excision; Manchester repair; anterior and posterior repairs; repair of enterocele; vaginal hysterectomy; post hysterectomy prolapse; treatment of stress incontinence by the cruciate bladder sling technique; repair of localized vaginal constriction; and repair of vesico-vaginal fistula. Volume 2 covers: Surgical anatomy and instruments; opening and closing the abdomen; abdominal hysterectomy; tubo-ovarian surgery; endometriosis; operation for acute pelvic inflammatory disease; appendicectomy; laparoscopy; cystourethropexy; ligation of internal iliac artery; drainage of abdominal wound haematoma; and abdominal closure of pelvic fistulae.

The life-size step-by-size photographs in both volumes are of uniformly high standard and extra clarity is achieved by the selective use of superimposed indicators. The accompanying commentaries are concise and follow the logical sequence of the photographs. There are also numerous simple line diagrams further to clarify photographs in which tissue planes, ligaments, skin edges, or the correct placing of incisions or sutures are not immediately self-evident. The common difficulties which may be encountered during operations are identified and methods of dealing with them are clearly described, e.g. the modification of the standard abdominal hysterectomy where there is a large cervical fibroid.

These atlases will be invaluable to trainee-specialists who wish mentally to rehearse an operation on a step-by-step basis. They are predictably expensive because of the profusion of colour photographs which so largely contribute to their success. Nevertheless, they represent a good investment for Departmental Libraries and we can look forward to the appearance of the remaining four volumes which will deal with: Operations for Malignant Disease; Surgery of the Vulva and Lower Genital Tract; Infertility Surgery; and Surgery of Conditions Complicating Pregnancy.

\section{Essential Intensive Care}

By E. Sherwood Jones. Pp. 503, illustrated. MTP Press: Lancaster, 1968. £9.95.

Of recent years, there has been such a proliferation of books on intensive care that any addition to their number must be exceptional if it is to arouse interest. Dr Sherwood Jones's vast experience in this field has enabled him, with the assistance of contributors of diverse specialities, to provide a comprehensive guide. The book is written for nurses attending a post-basic course and for junior doctors attached to a unit, and both groups of readers will find much of value. Not surprisingly, most space is devoted to respiratory intensive care, but renal and metabolic problems, alimentary failure, poisonings and coronary care are also covered. It is a pity that surgical problems receive relatively little attention.

On the whole, the book is a better guide to the clinical management of patients than to the underlying derangements in their physiology. The references at the end of each chapter, however, direct the reader to richer sources of information on scientific background. The text is lucid and, unusually in book with many authors, consistent throughout. The arrange $\bar{z}$ ment of the chapters seems a little strange. Why, for instance $\mathbb{D}$ is the one on ventilator treatment (an excellent exposition of the subject) separated from the equally good ones on: respiratory failure and oxygen therapy by 6 others on topics unrelated to the respiratory system? The style is didactic? which doubtless makes for clarity and simplicity, but does not always make a sharp enough distinction between matterso of fact and those of opinion. The number of spelling mistakes $\overline{\bar{n}}$. is prodigious.

This book would be used a great deal in any intensive carę unit wise enough to buy it. It would be even more com-ñ prehensive if it had more illustrations and were mores spaciously laid out, although these improvements would puto up the price, perhaps too much for nurses' pockets.

\section{A Colour Atlas of Oral Medicine}

By William R. Tyldesley. Pp. 111, illustrated. Wolfe. Medical Publications: London, 1978. £10.00.

The introduction to this work expresses the views of the book but really does not sustain the premise that it is for thoseco working in the field of dentistry, because of the variabilityos
of levels covered.

The book is definitely useful to a final year student or a revising postgraduate, but as for those practising oral $\frac{}{\supset}$ medicine as a speciality, it is unlikely to be on their shelves. -

The standard of photography is clear in most instances, $C$ however, the yellow sloughs in Figure 2 do not show clearly nor, for that matter, does Figure 7 clearly fill the caption. An arrow marker pointing to a particular point is always welcome. The caption relating to Figure 6 mentions tetracycline mouthwashes: the reviewer feels that the caution regardifg $\vec{\theta}$ age and tetracycline should have been made, having seen cases of tetracycline staining after a single short course of the antibiotic during the period of tooth development. Patients tend to swallow the mouthwash and indeed it may well control secondary infection both local and in the regional lymph nodes. In children under the age of 12 years, an antiseptic plus an analgesic, such as Paracetamol Elixir together with a high fluid intake and bed rest, appears to cope with the constitutional symptoms and the pain. The comments with Figure 8 should be thought about carefully, because $\frac{0}{3}$ with the degree of ulceration of the tongue shown, it would 3 be unlikely that the gingivae would not show some similar
erosions.

It is surprising that in discussing candidiasis, the relationship to antibiotic therapy was not made. Many patients, $\frac{0}{3}$ particularly with tetracyclines, suffer from thrush as a result of the therapy which may be localized or systemic, as shown in Figure 73: hardly the same section and not mentioned as in Figure 65. Other patients on steroids and on oral contraceptives, as well as patients at the extremes of age, are 3 susceptible to thrush, the steroid connection is mentioned later in the book in caption 165. It is here that oral medicine can be of help to medical colleagues whose patients may $D$ first present with oral thrush and mention they have a cough:음 this may be the result of pulmonary candidiasis. The treatment of thrush could well have been mentioned in order to be $\mathrm{N}$ consistent. The syphilitic lesions would have been better placed at the end of the section on infections of the oral $\mathrm{O}$ mucosa in order to give a better comparative flow to the cases $N$ illustrated.

The section on recurrent ulceration was clear but it would perhaps have helped if the term Mikulicz ulceration was 0 mentioned as another term for the major variety of aphthous $\Phi$ ulceration, also, although Figure 48 caption mentions coeliac disease, it would be helpful here to remind readers that this is found in some patients with recurrent minor aphthae and $\frac{T}{0}$ \title{
.
}


Crohn's disease (not specifically illustrated 126). It is noted in the diagnostic notes at the rear of the book, but readers do not look there spontaneously as they read through the sections.

In the caption to Figure 105, there would appear to be a confusion between Tzank cells and the Tzank test, in the latter, the intercellular bridges are lost in the prickle cell layer and the cells are rounded - this is the diagnosis for Pemphigus Bullae, but Tzank cells are the cells containing virus inclusion bodies found in association with the herpes and chicken pox viruses. The same comment can be made regarding caption 109.

It is surprising that the comment on Epanutin Hyperplasia was made regarding oral hygiene in a somewhat derogatory manner - it does not occur in excellent oral hygiene cases and also there is no mention of an apparently similar condition found in patients on Sodium Valporate (Epilim), furthermore, the vascular lesions shown are not usually neoplasms and should be put in a separate category; mention could have been made of 2 other inherited conditions, gingival fibromatosis with hypertrichosis and Hunter-Hurler syndrome with its mixed bone/mucosa changes. The state of a Mongol's tongue and mouth would be better shown that cancrum oris.

However, although one may be critical of certain aspects of the book, as a whole it makes a useful reference for the undergraduate and early postgraduate; also for general practitioners. The format would be better if the more common conditions, particularly on ulcers, came first and the notes came at the end of each section instead of the end of the book where they tend to be overlooked and to break the continuity.

\section{Essentials of Radiology}

By P. M. Bretland. Pp. 178, soft cover, illustrated. Butterworths: London, 1978. $£ 8.95$.

This is a soft covered book consisting of 178 pages. It has numerous line drawings for instruction and 230 problem radiographs for the reader to interpret. The radiological subjects covered are the chest, abdomen, bones and skull. No mention is made of contrast studies, and the author concentrates on plain film interpretation. There is a list of suggested books for further reading included.

In the preface Dr Bretland says that the book is intended for the student in his first clinical year. The reviewer was quite pleased when he read this, as he has felt for a long time that there is a great need for such a book in diagnostic radiology. However, he thinks that the first year clinical student might find some of the pathological disorders beyond his grasp. It is possible, of course, that he may be stimulated to refer to other medical text books for elucidation. The content would be of greater value to the young postgraduate and indeed helpful to those intending to pursue a career in diagnostic radiology. The emphasis is on a basic scheme of approach and in this the author has succeeded. The steps to be taken in "reading" the plain X-rays of the areas covered are very clearly stated.

This reviewer can find no fault with the text, which is well written and easy to read. However, he found many of the photographic prints difficult to interpret, because the lesions were not clearly seen. This is a fault of the reproduction, and the reviewer is worried lest many non-radiological readers might be discouraged by a failure to achieve a worth-while diagnostic score. Even on reading the well written descriptive answers, the lesions in many were still not visible. This is unfortunate because the radiographs are well chosen and cover a wide area of different pathologies. It is hoped that in future editions this fault will be corrected.

Allowing for this, the reviewer would recommend this book to all those students and young postgraduates who are looking for a clear account of how to interpret the plain radiographs they will see in daily practice. This has been a relatively neglected area in most radiological text books and Dr Bretland has gone some way to correcting it.

\section{Gastroenterology. An Integrated Course}

(2nd Edition). By Iain E. Gillespie and T. J. Thomson. Pp. 294, illustrated, soft cover. Churchill Livingstone: Edinburgh, 1977. £3.95.

This book, which is based on a course given to 4th-year students at Glasgow Medical School, is primarily intended for an undergraduate audience. An integrated approach has been adopted and the whole of medical and surgical gastroenterology, including a chapter on the mouth, and a chapter on gastrointestinal disease in general practice are dealt with in 284 pages. Consequently only basic facts are presented and controversial issues are strictly eschewed. Something of a surgical bias is also detectable, with only 34 pages dealing with liver disease, whereas 22 pages are devoted to the proctodaeum.

Despite its multiple authorship the book is ably and uniformly written and it is well illustrated throughout. Simple line drawings are employed to clarify the text and there are good quality reproductions of X-ray and histological material. The book should appeal particularly to those medical students desirous of a didactic approach. It is of doubtful value, however, for the postgraduate.

\section{Gynaecological Laparoscopy \\ The Report of the Working Party of the Confidential Enquiry into Gynaecological Laparoscopy}

Edited by G. Chamberlain and J. Carron Brown. Pp. 165, illustrated. Royal College of Obstetricians and Gynaecologists: London, 1978. £2.50.

A survey of patients undergoing gynaecological laparoscopy in the United Kingdom was carried out between April 1st 1976 and March 31 st 1977 and the information contained in over 50000 completed questionnaires has been duly analysed and presented in book form. A facsimile of the questionnaire form is included at the end of the report.

It is difficult to see who will benefit from reading this report, nor is it possible to assess whether the results justify the enormous expenditure of effort and time on the part of so many practising doctors. Those who have been using the technique for a number of years are not going to learn anything that they were not aware of already and those in training, both gynaecologists and anaesthetists, will learn more quickly and in greater depth if they work for seniors already versed in the procedure. It is to be hoped that this report does not open up a floodgate for similar ones dealing with other forms of endoscopy. All investigational techniques carry some hazard and it behoves clinicians to weigh up advantages of any technique before employing it. Once adopted, then the risk factors will be taken into account each time it is used and a report such as this is not going to influence the decision.

Man at High Altitude. The Pathophysiology of Acclimatization and Adaptation

By Donald Heath and David Reid Williams. Foreword by Sir Cyril Astley Clarke. Pp. 292, illustrated. Churchill Livingstone: Edinburgh, London, New York. £12.50.

This book incorporates the wide personal experience over the past decade of the authors in the study of Man at High Altitude in the Andes and subsequently extrapolated to the laboratories of the Department of Pathology at the University of Liverpool. The pathophysiology of acclimatization and adaptation to high altitudes is described dealing both with the clinical and pathophysiological aspects of all organ systems which may be effected. This book has particular 